\title{
Nonionic Model Microemulsions to Study Interactions with Active Components and Antioxidant Activity
}

\author{
Joakim Balogh ${ }^{1,2}$, Luís Marques ${ }^{1}$ and António Lopes ${ }^{1}$ \\ ${ }^{1} I T Q B$ Oeiras \\ 2Physical Chemistry Lund University \\ ${ }^{1}$ Portugal \\ 2Sweden
}

\section{Introduction}

This chapter reviews and presents the latest developments on the work on using nonionic microemulsions stabilized by surfactants of ethylene oxide alkyl ether type, $C_{m} E_{n}$, where $m$ is the number of carbons in the alkyl chain and $n$ is the number of ethylene oxide groups as models to determine the effect of an added component. We will here investigate if active components can be added to this model drug delivery system without them affecting the system. This is important as there is now several "ready to use" drug delivery systems where one just need to add an active component. We will here see if it is as simple as this or if more work will be required with these formulations.

These model systems stems from research based at Lund University (Olsson \& Schurtenberger, 1993) that has been thoroughly investigated and characterized (Balogh, Olsson \& Pedersen, 2006, Balogh et al. 2007, Le et al., 1999 Leaver et al., 1994, Leaver et al., 1995, Olsson \& Schurtenberger 1993). The effect of changing the alkane (decane changed to hexadecane) has also been studied (Balogh et al., 2006, Balogh, Olsson \& Pedersen, 2006, Balogh et al. 2007, Balogh \& Olsson 2007). The surfactants and similar systems have been thoroughly investigated trough the massive work by Shinoda and Kuneida (Shinoda \& Kunieda, 1973) in Yokohama, Japan and Kahlweit and Strey (Kahlweit et al, 1985) Göttingen, Germany, later Strey and Sottmann (Sottmann \& Strey, 1996) with coworkers in Cologne, Germany. More about the early days of these surfactants and systems can be found in these references (Balogh et al., 2010, Lindman 2008). As with most systems the investigations of the phase boundaries are essential. As these systems are temperature sensitive through their surfactant they can change phases by just having the temperature changed. There is also no need for co-surfactants or co-solvents to be able to have a wide variety of phases. It is possible with a small number of samples to study changes into several phases. As the structures are thermodynamically stable one can go up and down in temperature to determine the boundaries more accurately. For the studied system the phase changes are fast and go from turbid to clear, making them easier to investigate. Amongst its many uses (Fanun 2009, Kunieda \& Solans 1997) microemulsions have been used as drug 
delivery systems since long time and have been investigated as such (Garti et al., 2004, Gupta \& Moulik, 2008, Heuschkel et al., 2008, Kreilgaard et al., 2001, Lawrence \& Rees, 2000, Spernath \& Aserin, 2006) especially topical formulations (Grampurohit et al., 2011, Kreilgaard 2002). Nonionic microemulsions of the $C_{m} E_{n}$ type has been studied regarding the effect of adding lidocaine (Balogh \& Pedersen 2007, Balogh et al 2010). It has also been used as a membrane to study the effect of other analgesics on membranes (Baciu et al., 2007). Microemulsions are usually used to get hydrophobic active components into solution. Microemulsions are also reported to improve drug delivery and as such they are more than just a passive vehicle for the active component. It is an active vehicle that improves the performance of the formulation (Bagwe et al., 2001, Kogan \& Garti 2006) especially on topical formulations (Lopes et al., 2010, Santos et al., 2008, Sintov \& Levy, 2007). It is therefore important to study the interaction between the active component and the drug delivery system to better know the boundaries of the system. This gives better knowledge on the shelf-life of the formulations. Lidocaine is amongst other used as local anesthetic in dermal creams and is as such, a good candidate as a model drug for a drug delivery system aimed for topical delivery. It is well known that having a hydrophobic compound, which is sensitive to oxidation, in a microemulsion or an emulsion help protect this compound (Gaonkar \& Bagwe, 2002). It is also possible to have extra protection by having antioxidant in the system and if formulated well one can have antioxidants in both the oil- and water phase. Antioxidants have now also become a component that is added to many formulations to act as active component and not only to protect other components. This is extra common in skin products where vitamin $\mathrm{E}$ is a component that helps sell the products, often labeled as tocopherol acetate, tocopheryl linoleate or tocopheryl nicotinate (Nabi et al., 1998). Some studies have shown that applying vitamin E before UV exposure significantly reduces acute responses such as edema and erythema (Bissett et al., 1992). Topical application is related to decrease of the incidence of ultraviolet UV-induced skin cancer (Krol et al., 2000, McVean \& Liebler, 1999). The form of vitamin E that is preferentially absorbed and accumulated in humans is a-tocopherol (Rigotti, 2007). These formulations show many similarities to the model system used here. There is also a trend with "natural" antioxidants in many kinds of products from juices to shampoos and skin products. One fairly available antioxidant is chlorogenic acid, a polyphenol with a dry matter content in coffee beans on 4-14\% depending on coffee species (Clifford et al., 1985, De Maria et al., 1994, Ky et al., 2001, Trugo \& Macrae, 1984). From the chlorogenic acids family (caffeoylquinic acids), the most reported isomers are, 3-CQA, 4-CQA and 5-CQA. 5-CQA is the most abundant compound found in coffee beans, responsible for about 56-62 \% of total chlorogenic acids (Ramirez-Colonel et al., 2004, Ramirez-Martinez 1988). It is also the most abundant antioxidant in coffee foliage (Marques, 2011). It has been getting a lot of attention and the reported health benefits both in vivo and in vitro, from chlorogenic acids are hepatoprotective, immunoprotective, hypoglycemic and antiviral activities (Basnet et al., 1996, Natella et al., 1998, Scalbert \& Williamson, 2000). We are using 5-CQA as our type chlorogenic acid.

Phase studies give a lot of essential information about the system and it has even been done to make sure that the batch of surfactant used is good by constructing a known phase diagram. With three ingoing components and temperature the full spectra of the systems could be illustrated with a phase prism. To optimize the ratio between work and information some cuts (fixing ratios of components) have been used. Three classic ones are the Shinoda cut (Kunieda \& Shinoda, 1982) with fixed surfactant ratio varying the water to oil ratio, to investigate the 
reversal of the system amongst others, the Kahlweit cut (Kahlweit \& Strey, 1985) with fixed water to oil ratio often 1:1 on volume base, to investigate the efficiency of the surfactant amongst others, and the Lund cut (Olsson \& Schurtenberger, 1993) with fixed ratio of surfactant to oil, often $0.815: 1$, to study the microemulsion aggregates concentration dependence. The Kahlweit cut is also known as the fish or the fishtail cut due to shape of the 3-phase body and the microemulsion phase. Even though the Lund cut is from the nineties it is only named recently (Balogh, 2010, Balogh et al., 2010). The phase cuts are illustrated in Figure 1.
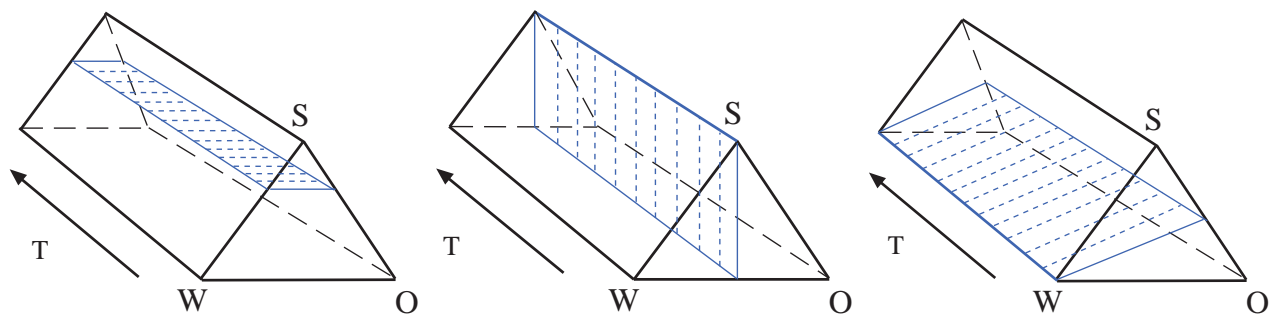

Fig. 1. Phase cuts. Here three different phase cuts are illustrated from the Shinoda cut on the left with the Kahlweit in the middle and the Lund cut to the right. T stands for temperature, $\mathrm{W}$ for water, $\mathrm{O}$ for Oil and $\mathrm{S}$ for Surfactant.

With these systems there are some trends that can be used to help in determining a new system and there is also some scaling. For the Lund system using alkanes and $\mathrm{C}_{12} \mathrm{E}_{5}$ the trend is that the lowest temperature where one can have microemulsions, $T_{\mathrm{EFB}}$, increases with the length of oil from octane to octadecane. The microemulsion temperature range, the temperature increase one can do from $T_{\mathrm{EFB}}$ and still have 1-phase microemulsion, decreases with increased oil length (Balogh, 2010, Balogh et al., 2010). This is a general finding for all these systems. There have also been reports on the lamellar phase and that it is not only becoming smaller but actually withdrawing gradually to high concentrations only, with aggregates volume fractions above 0.5 (Balogh, Olsson \& Pedersen, 2006, Balogh, 2011). We have not seen reports if this is a general finding for these types of systems or not.

\section{Result}

We will here present the standard system comprised of $\mathrm{C}_{12} \mathrm{E}_{5}$, decane and water (surfactant, oil and water) with phase studies and then diffusion studies both at the emulsification boundary and at elevated temperatures. We will then present the systems with an extra added component both phase studies, studies of the zeta potential and diffusion and compare with the standard system. This will be followed by the studies of the antioxidant activity both individually in the microemulsion compared to in a pure solvent and together in the microemulsion.

\subsection{Studies of the system $\mathrm{C}_{12} \mathrm{E}_{5}$ decane and water}

The samples were performed prior to using by diluting a stock-solution of surfactant and oil $\left(\mathrm{C}_{12} \mathrm{E}_{5}\right.$ :decane $0.815: 1$ on volume base) with water in the water rich region. The stocksolution volume fraction, $\Phi$, stretched the $0.005-0.2$ region but was mostly investigated in the 0.05-0.2 region. The samples where then mixed above the upper phase boundary (turbid 
two-phase region) for five minutes and then cooled while stirred into the microemulsion region (clear one-phase solution). They were stored at this temperature until used.

\subsubsection{Phase studies of the system $\mathrm{C}_{12} \mathrm{E}_{5}$ decane and water}

We will here present mostly work using the original type system for the Lund cut, $\mathrm{C}_{12} \mathrm{E}_{5}$, decane and water. A phase diagram for the microemulsion phase that we are working in is shown in Figure 2.

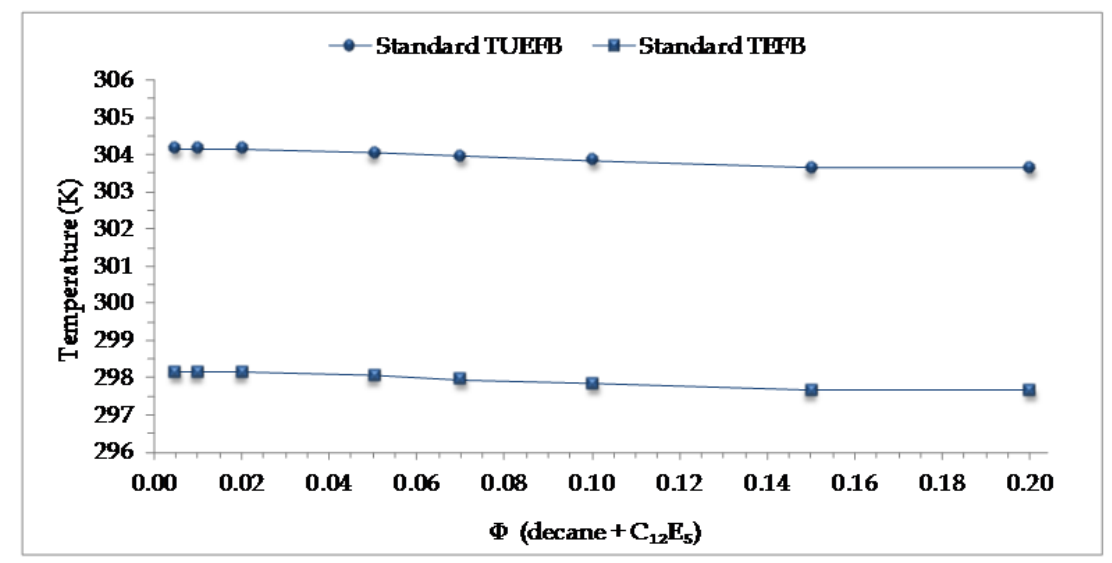

Fig. 2. Partial phase diagram for the standard system $\left(\mathrm{C}_{12} \mathrm{E}_{5}\right.$, decane and water $)$ showing the upper (spheres) and lower phase boundaries (squares) temperatures for the microemulsion phase in the water rich region with the surfactant and oil concentrations from $\Phi=0.005$ to 0.2 .

A comprehensive phase diagram has been determined earlier (Le et al., 1999). This shows that above the microemulsion phase is a lamellar phase and even further up in temperature is a bicontinuous bilayer phase. At higher concentrations just above volume fractions of 0.4 starts liquid crystalline phases like cubic and hexagonal. We have been working in a more limited area of the range mostly in the microemulsion phase with aggregate ratios, $\Phi$, mostly from 0.05 to 0.2 . This is done to have as little impact from crystalline structures at higher concentrations and from the edge of the dilution limit as possible. It can be hard to follow the system visually at the highest dilutions with $\Phi$, from 0.005 to 0.02 as they tend to look "clear" even when there is two phases. Initially at the lower phase boundary it starts as discrete aggregates that, at the lower concentrations, are spherical and towards the upper boundary the system becomes bicontinuous. The higher the concentration the lower is the increase in temperature needed to change into bicontinuous system (Balogh \& Olsson, 2007, Balogh et al. 2007, Leaver et al., 1994, Leaver et al., 1995). The change happens without macroscopic phase change.

\subsubsection{Diffusion studies of the system $\mathrm{C}_{12} \mathrm{E}_{5}$, decane and water}

With increased temperature the curvature of the surfactant film decreases. As long as one is below the lower emulsification boundary and thus has access to more oil, the aggregates essentially just grow as spheres and become bigger spheres. So at the emulsification 
boundary the aggregates are spherical at least at lower concentrations. At higher concentrations and especially for longer oils the aggregates become slightly elongated already at the emulsification temperature (Balogh, Olsson \& Pedersen, 2006). The growth of these aggregates has been shown to best fit with the one-dimensional ellipsoidal growth (rugby ball) (Leaver et al., 1995). The growth before changing into bicontinuous does not extend axis ratios of 4-6 big axis to small axis (Balogh \& Olsson, 2007, Balogh et al. 2007, Leaver et al., 1994, Leaver et al., 1995). Earlier reports of elongated micelles did not investigate if the aggregates had changed into the bicontinuous phase as defined by the self diffusion of the surfactant being different from that of oil (for an oil-in-water system). The behavior in scattering terms of the bicontinuous system is initially such that it easily could be confused with elongated micelles. As there is no macroscopic phase change it is not seen any change when performing phase studies of the microemulsion phase. When performing light scattering experiments one need to remember that for dynamic light scattering one is studying collective diffusion. Collective diffusion has a concentration dependence that makes it important to have in mind when comparing different concentrations. It also means that the size coming from the light scattering machine has not taken this into account as it just using the Stokes Einstein equation to get size from diffusion.

$$
D_{0}=\frac{K_{b} T}{6 \pi \eta r}
$$

Here $D_{0}$ is the diffusion at infinite dilution, $k_{B}$ boltzmann constant, $\eta$ viscosity and $r$ radius of the aggregate. From this it is easy to see how the size depends on the diffusion in this case at infinite dilution and with spherical aggregates.

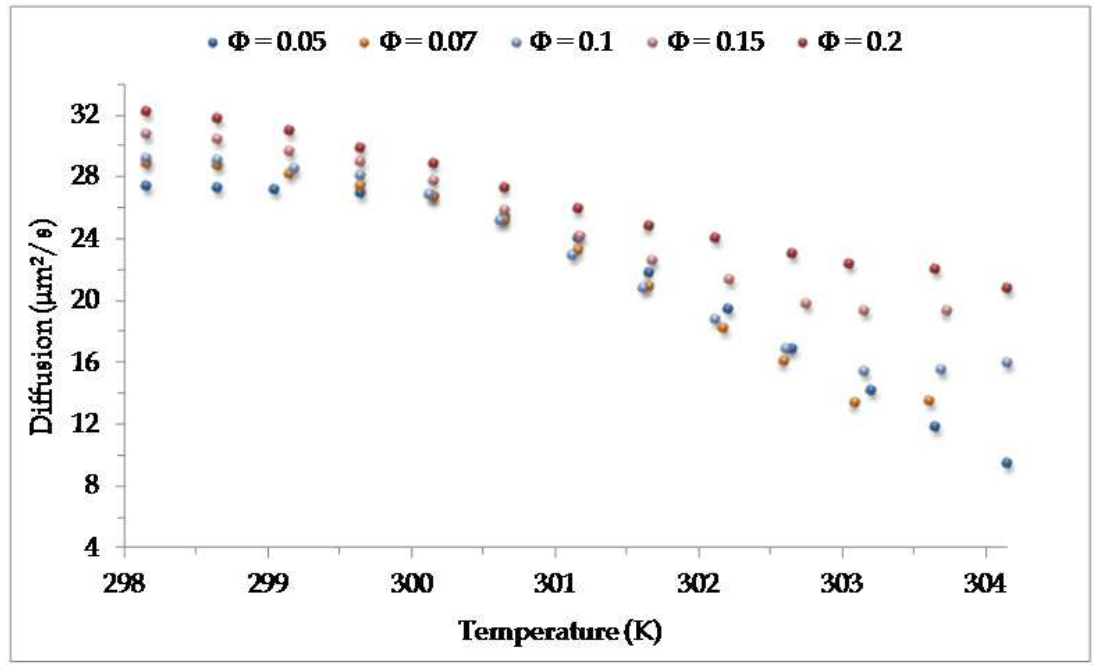

Fig. 3. Diffusion versus temperature for five droplet concentrations from $\Phi=0.05$ to 0.2 .

When looking at Figure 3 for one temperature it seems as if the higher the concentration the higher the diffusion. Just applying Stokes Einstein equation would give smaller size with higher concentration. This is however not the case as we will show. If one want to compare 
different concentrations it is important that one have the concentration dependence of the collective diffusion in mind. The hard sphere behavior (if there is no growth in the system or repulsion/attraction between the aggregates) is $D_{\mathrm{C}} / D_{0}=1+\Phi_{\mathrm{HS}}{ }^{*} 1.45$. Where $D_{\mathrm{C}}$ is the collective diffusion, $D_{0}$ is the diffusion at infinite dilution and $\Phi_{\mathrm{HS}}$ the hard sphere volume fraction, for these systems 1.14 times that of the aggregate volume fraction (Olsson \& Schurtenberger, 1993). If the result is presented as the diffusion normalized with the diffusion at infinite volume fraction at each temperature (to just have the effect of concentration at each temperature), as in Figure 4, one can see that the difference from the hard sphere behavior is bigger at higher temperatures and concentrations. It has earlier been shown that there is no attraction in these systems that would explain this so the only explanation left is that the aggregates grow. This has been shown to be the case (Balogh \& Olsson, 2007, Balogh et al. 2007, Leaver et al., 1994, Leaver et al., 1995). At higher temperatures the aggregates are more elongated and also becomes bicontinuous so that the diffusion do not give a good representation of the aggregate size just some form of repeated unit in the structure and the perceived diffusion may even go up.

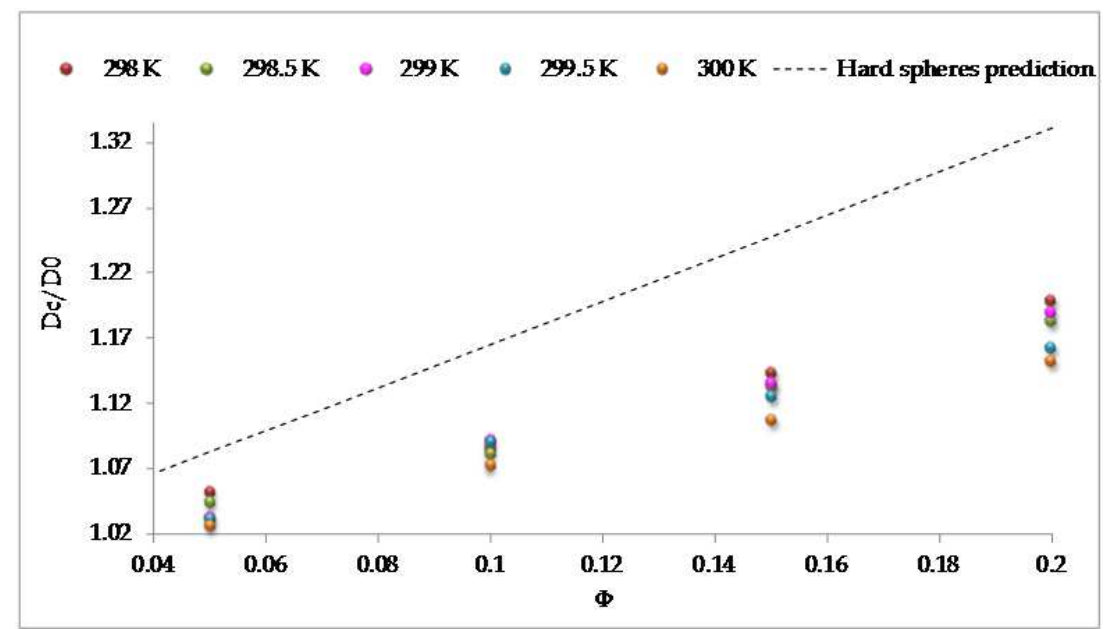

Fig. 4. Diffusion versus droplet concentration from $\Phi=0.05$ to 0.2 for several temperatures with the collective diffusion behavior for aggregates acting like hard spheres as reference.

Just to once again mention the effect of changing the alkane one would see the same thing as in Figure 4 that the higher temperature the faster they grow with concentration but with increasing chain length. This is seen as the slope of the fitted line would be lower and further away from the hard sphere behavior with increasing chain length or temperature (Balogh, Olsson \& Pedersen 2006, Balogh, 2011).

\subsection{Studies of the system $\mathrm{C}_{12} \mathrm{E}_{5}$, decane and water with an added component}

As the model system is well characterized it is easier to study the effect of adding a fourth component to the system especially if one will work with limited number of techniques. Generally the systems used for drug delivery are more complex and often not studied as thoroughly as our model. The findings from an applied system need to be complemented 
with more techniques to explain what happen on aggregate level. The addition of three different components has been studied. The components are different as one is a local anesthetic, oil soluble and slightly water soluble (20:1 solubility in decane:water) and the other two are natural compounds that act as antioxidants. The antioxidants are different as chlorogenic acid, CQA, is water soluble and $\alpha$-tocopherol is oil soluble. The molecular structures are shown in Figure 5.

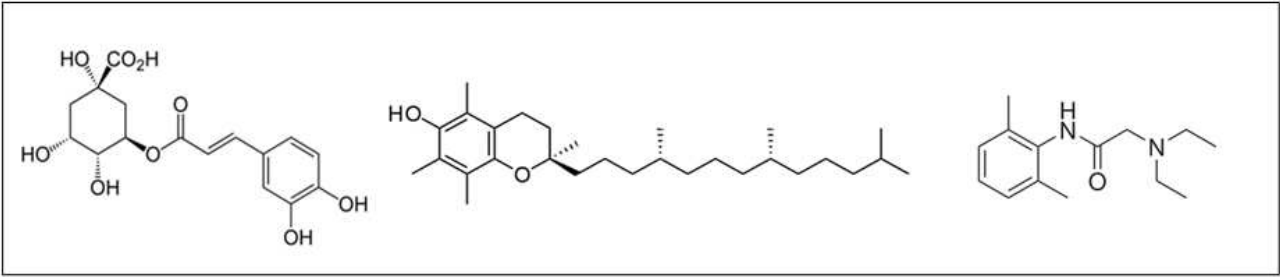

Fig. 5. Molecular structure for the added components. From left to right chlorogenic acid, $\alpha-$ tocopherol and lidocaine.

To try to keep the lipophilic component constant part of the oil was substituted with lidocaine and a-tocopherol respective. The system was close to the limit of how much that could be solved with $10 \%$ volume fraction of lidocaine in decane. When adding the surfactant it was no problem to keep it in solution, even in the fridge. The solubility of lidocaine in water was low but there was some solubility estimated to $0.5 \%$ giving a ratio of solubility between decane and water to 20:1. There was no problem in solving 10 volumes percent of a-tocopherol in decane. We dissolved a maximum of $2 \%$ CQA in water. Tocopherol had very low solubility in water and is often reported as insoluble in water. The solubility of CQA in decane was low. We used the oil with the added substance as "oil" when preparing our stock solution and used water containing CQA to dilute the stock solution when preparing our measurements. From this it is seen that the concentration of CQA was almost constant regardless of the aggregate concentration (giving different ratio). We added 1, 5 and 10 volume percent of lidocaine giving the active compound content of the total system of $1 \%$ with a $10 \%$ addition and with an aggregate fraction of 0.2 . The local analgesic EMLA ${ }^{\circledR}$ from AstraZeneca contains 2.5\% lidocaine so the concentrations used are similar to the formulations used today. Concentrations of 2\% CQA are much higher than that of coffee and with a maximum of $1 \%$ of $\alpha$-tocopherol on total formulation it seems to be above what is used in formulations today.

\subsubsection{Phase studies of the system $\mathrm{C}_{12} \mathrm{E}_{5}$, decane and water with an added component}

The first thing that needs to be done was to perform phase studies and determine the phase diagram with the additions. In Figure 6 we show the temperature of the lower phase boundaries for different droplet concentrations and different addition of CQA. There is a small but increasing difference in temperature with droplet concentration much more than in the standard and for the other additions.

As the concentrations of the antioxidant components are relatively high compared to many formulations, it was necessary to also study the effect at lower concentrations and for concentrations CQA $0.005-0.02 \%$ the change from standard was small. From here it is seen that not only the temperature where the microemulsion form changes, but also the upper boundary. 
However the upper boundary does not increase as much as the lower giving a smaller microemulsionrange. The range becomes smaller with higher CQA concentration (and by that the temperature of the emulsification boundary). A similar thing has been seen in system where the oil length has been varied, the lower the temperature the bigger the range. This gives that shorter alkanes has bigger microemulsion temperature range than the longer ones.

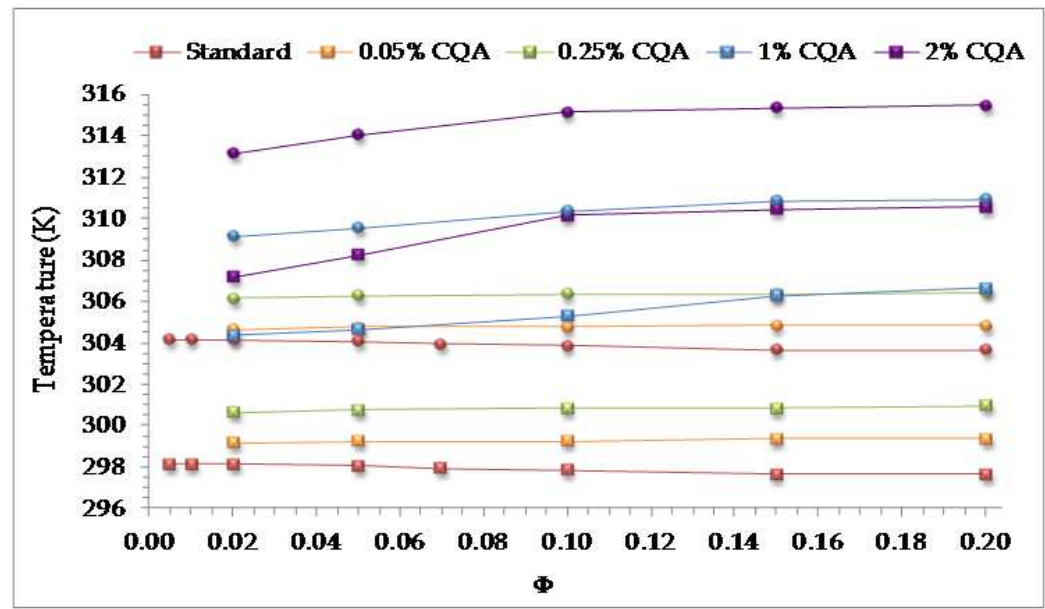

Fig. 6. Partial phase diagram in the water rich region showing the upper (spheres) and lower phase boundaries (squares) for the microemulsion phase with the surfactant and oil concentrations from $\Phi=0.005$ to 0.2 and with $0.05-2 \%$ of water substituted with chlorogenic acid.

Phase investigations were also performed for the system with added lidocaine. As can be seen in Figure 7 there is a significant change when increasing the substitution.

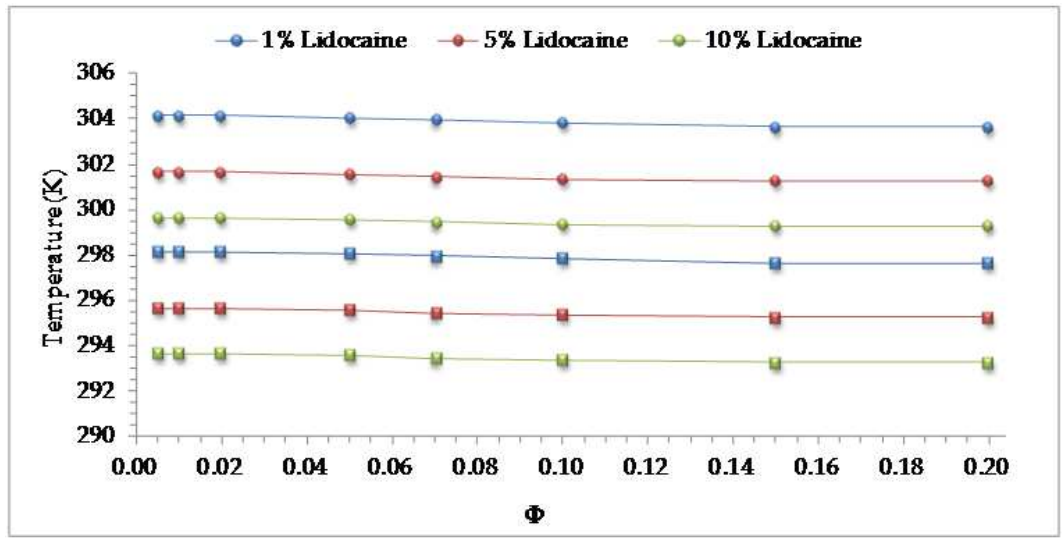

Fig. 7. Partial phase diagram in the water rich region showing the upper (spheres) and lower phase boundaries (squares) for the microemulsion phase with the surfactant and oil concentrations from $\Phi=0.005$ to 0.2 and with 1,5 and $10 \%$ of the oil substituted with lidocaine. 
The phase boundaries of the standard system are very close to that of a $1 \%$ substitution with lidocaine. One can also see that with increasing aggregate concentration the phase boundaries are lowered slightly.

Finally phase investigations were performed on the systems with added $\alpha$-tocopherol and below are shown the resulting phase diagram in Figure 8.

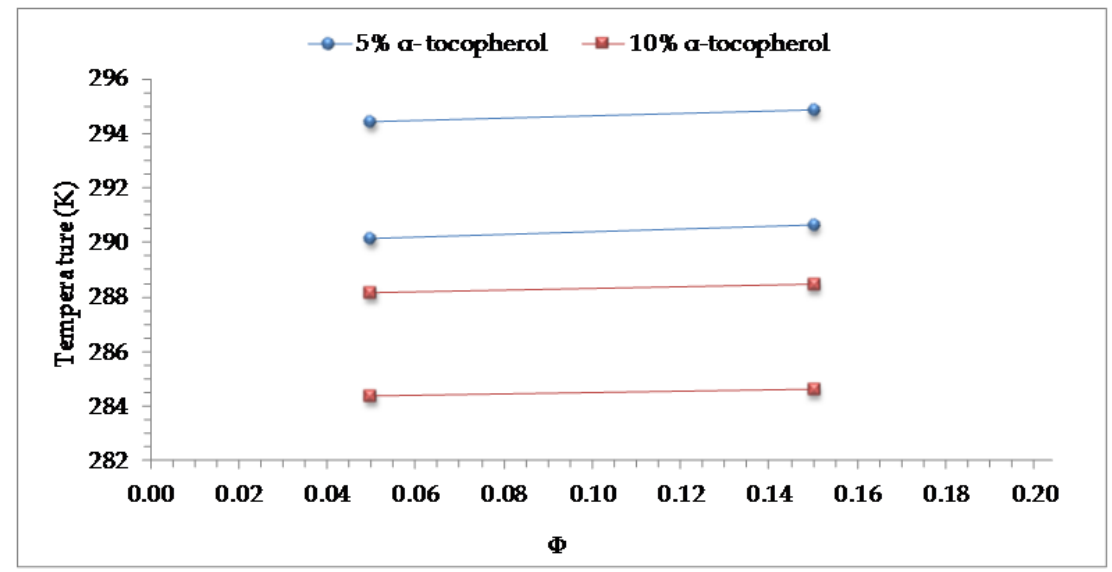

Fig. 8. Partial phase diagram in the water rich region with the surfactant and oil concentrations $\Phi=0.05$ and 0.15 with 5 and $10 \%$ of the oil substituted with $\alpha$-tocopherol.

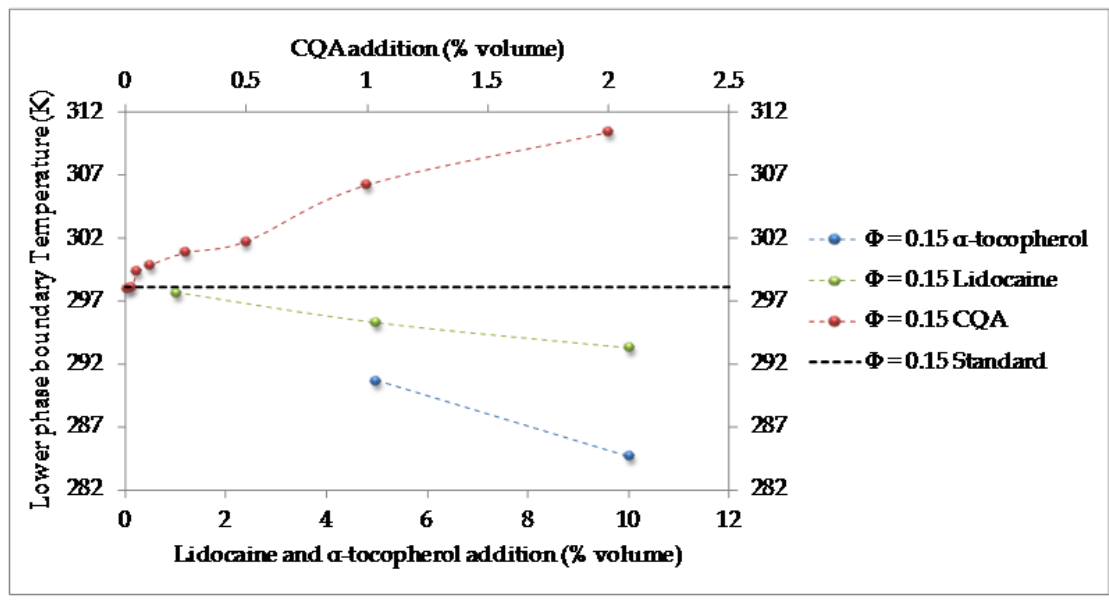

Fig. 9. Partial phase diagram in the water rich region with the surfactant and oil concentrations fixed at $\Phi=0.15$ with varied amount of the oil substituted with $\alpha$-tocopherol and lidocaine, and water substituted with CQA.

Here there is a slight increase of phase boundaries with temperature. The substitution with $\alpha$-tocopherol makes a bigger impact than the same substitution with lidocaine. The temperatures of the phase boundaries are lowered far from the standard system with 298 as 
lower boundary and for $5 \%$ substitution this is above its upper phase boundary. This dramatic phase change needs to be addressed when formulating with this high concentrations. Below Figure 9 is showing that the lower phase boundary of CQA is increasing the temperature and that lidocaine and especially $\alpha$-tocopherol is lowering the temperature. Here, all of the data is for a droplet ratio of 0.15 .

The increase caused by the substitution with CQA is big compared to the others looking at their part of the solvent. As there is more water than decane the change with number of molecules are similar between CQA and $\alpha$-tocopherol but higher than that of lidocaine.

\subsubsection{Zeta potential studies for the system $\mathrm{C}_{12} \mathrm{E}_{5}$, decane and water with an added component}

The effect of the substitution with CQA was very strong and in order to try to find out why, more investigations were performed. As CQA can be charged in water the possibility of the aggregates also being charged was investigated. Zeta potential measurements were performed and a small Zeta potential was noted. The standard system did not show any zeta potential. To study if it was a "real effect" and not just a coincidence repeated experiments were performed varying the concentrations of the ingoing components. Figure 10 shows the fixed concentration of CQA and the variation of the aggregate concentration.

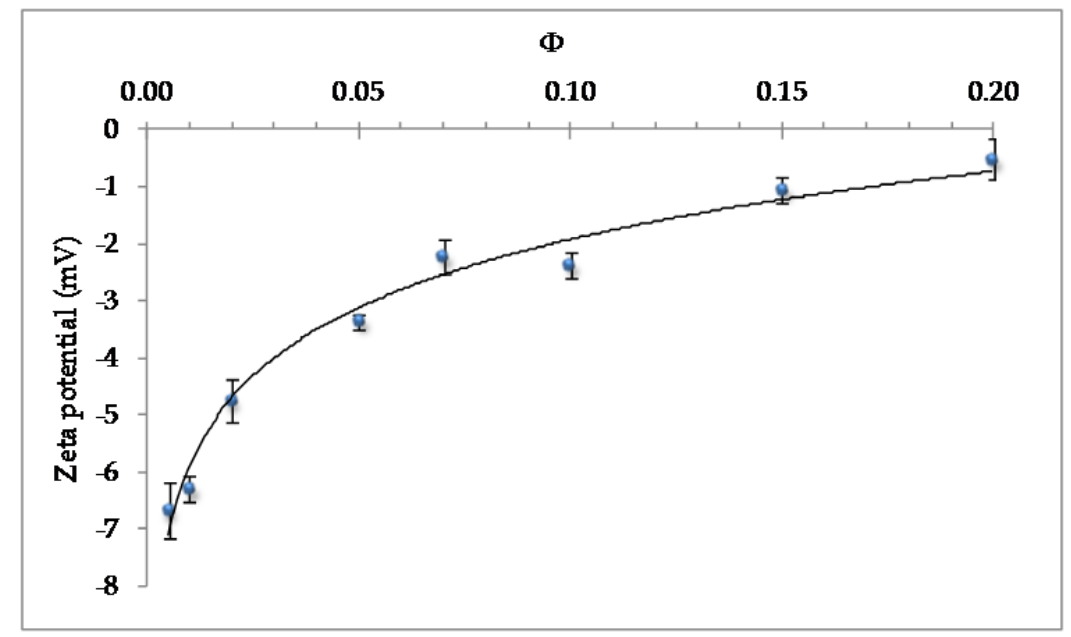

Fig. 10. Zeta potential for different aggregate concentrations with fixed $1 \%$ CQA concentration (triplicate measurements, and standard deviation in the error bars).

As can be clearly seen there is a concentration dependence and the aggregates with most charges are also the ones that has most CQA per aggregate (lower droplet concentrations). To be certain of the effect we also varied the CQA concentration and had fixed aggregate concentration. This is shown in Figure 11.

Here one can also see the relation with charge of the aggregate and the CQA concentration. From here it is evident that the aggregates behave as if they are charged. Up to a bulk 
concentration of $2 \%$ the concentration in the bulk influence the apparent charge of the aggregate. If the charge is connected to the aggregate or if it is several charges that shift and by its close presence to the aggregate make it appear charged is not determined yet. It was not enough to have a charged bulk water to get aggregates that appeared to be charged, as was seen when using sodium chloride with the same charge (Balogh et al., 2012). This had no or minimum effect on the phase boundaries, the zeta potential (had none) and the diffusion compared to the standard system. Lidocaine did not show any effect on the zeta potential even if it had some solubility in water. Tocopherol was not studied as it has so low solubility in water that we did not expect to see any effect.

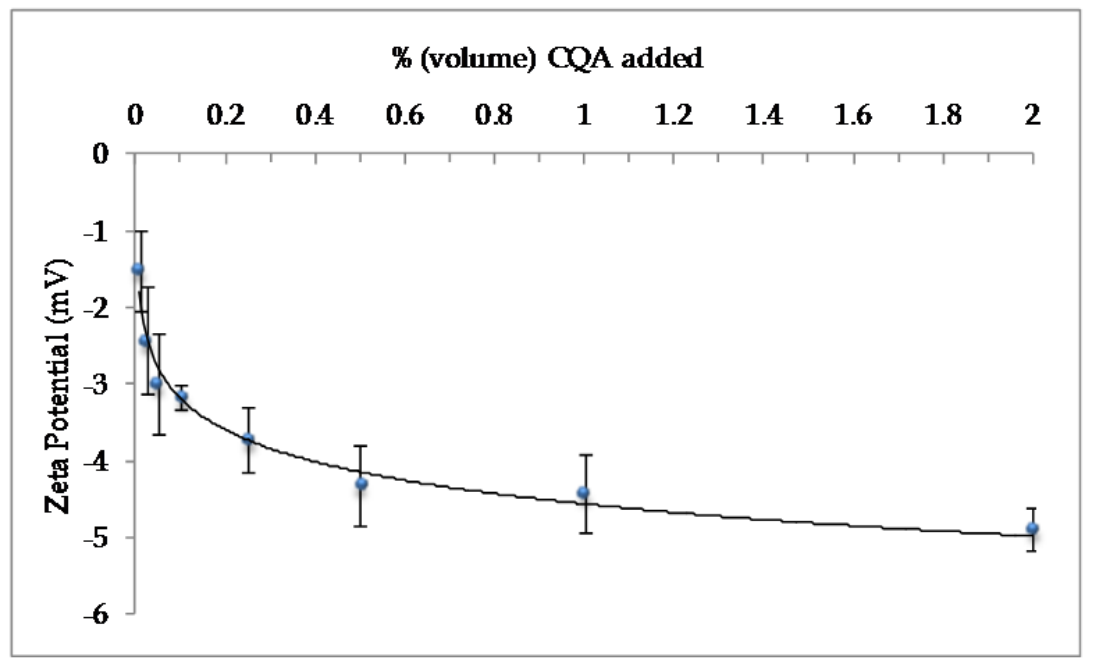

Fig. 11. Zeta potential for different CQA concentrations with fixed aggregate concentrations $\Phi=0.05$ (triplicate measurements, and standard deviation in the error bars).

\subsubsection{Diffusion studies for the system $\mathrm{C}_{12} \mathrm{E}_{5}$, decane and water with an added component}

The diffusion of the system with added compounds did change a bit from standard part of it, which was due to the different temperature range of the microemulsion phase and by that the measuring temperature. To eliminate this temperature effect the curves where normalized with their respective diffusion at the temperature of lower phase boundary. Then one can see that the curves also are slightly different as can be seen from Figure 12. Here one can look at the shape of the curve and compare to see that they have a very similar behavior. For small additions it was hard to see any significant difference but at higher concentrations the profile is slightly different showing that the growth of the aggregates and the temperatures where the systems change into bicontinuous aggregates differs from that of the standard system.

The small differences in how these systems behave with temperature, and hence when they change from discrete aggregates to a bicontinuous system, may influence a lot of properties for a formulation, such as the availability of drug and stability of the formulation, and thus important parameters to be aware of. 


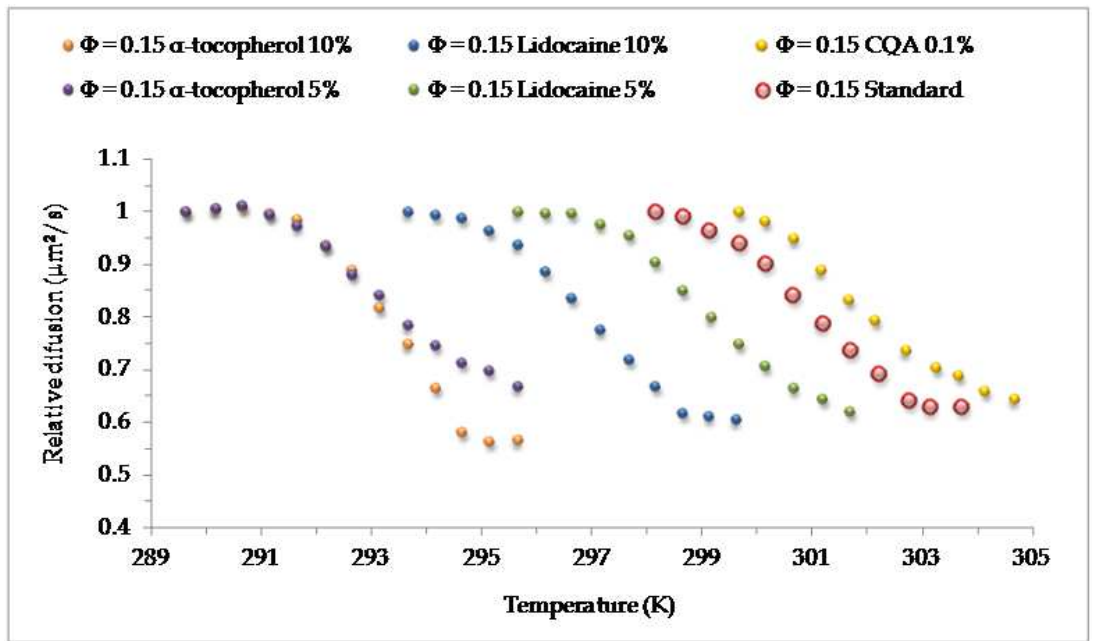

Fig. 12. Relative diffusion the collective diffusion normalized with the diffusion at the respective phase boundary temperature for several systems with added components.

\subsection{Studies of the antioxidant properties in the microemulsion}

Even though antioxidants can be used to manipulate the phase boundaries, their primary function would be to act as antioxidants either to protect an active component or themselves as main components. It was hence important to confirm that the antioxidants still had the capability to interact with oxidants if these would appear in the microemulsion. We determined the antioxidant activity by using a dye that is a radical 2,2-diphenyl-1-picrylhydrazyl (DPPH) hence after called DPPH. The structure of DPPH is shown in Figure 13

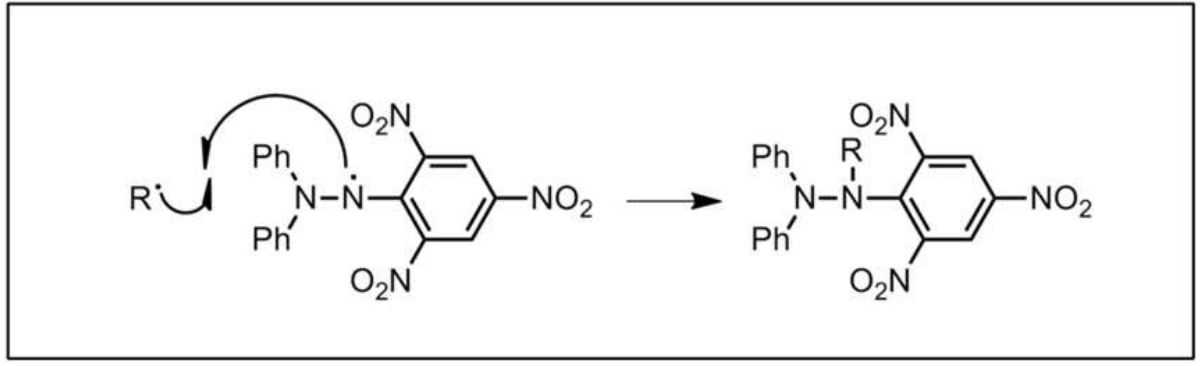

Fig. 13. The molecular structure of 2,2-diphenyl-1-picrylhydrazyl (DPPH) and then when it has reacted with another radical.

The problem is to have a system where a dye can be used to test both hydrophobic and hydrophilic compounds. DPPH is soluble in methanol and in decane and it fits our purpose. An added dye may influence the phase boundaries but at the concentrations used here, up to $60 \mu \mathrm{mol} / \mathrm{L}$, there were no significant changes. First a calibration curve of DPPH was prepared. Then the values after the addition of antioxidant were compared to this to get the 
concentration. As DPPH is a strong dye, the concentrations that could be used and still be in the region where there is a good linear correlation between absorption and concentration, was quite low as stated earlier (up to $60 \mu \mathrm{mol} / \mathrm{l}$ ). This also influenced the maximum concentrations of the antioxidants. It was also possible to use DPPH in decane used to prepare the stock solution for the microemulsion experiments.

\subsubsection{Studies of the antioxidant properties of CQA in the microemulsion}

We could determine the effect of CQA with DPPH in a methanol solution and then compare that with the effect in the microemulsion. In the microemulsion we dissolved the DPPH in the decane used in our microemulsion and CQA was in the water used to dilute the microemulsion stock solution. This way we did not need to add anything that would influence the microemulsion more than the dye itself. The dye was in such low concentrations that it did not influence the microemulsion phase boundaries. We were somewhat limited in the amount of DPPH we could have in the decane for the microemulsion but not significantly and we were able to have a good concentration interval. Even though DPPH was in decane and CQA in water, CQA had the same effect as if both were in methanol as seen in Figure 14.

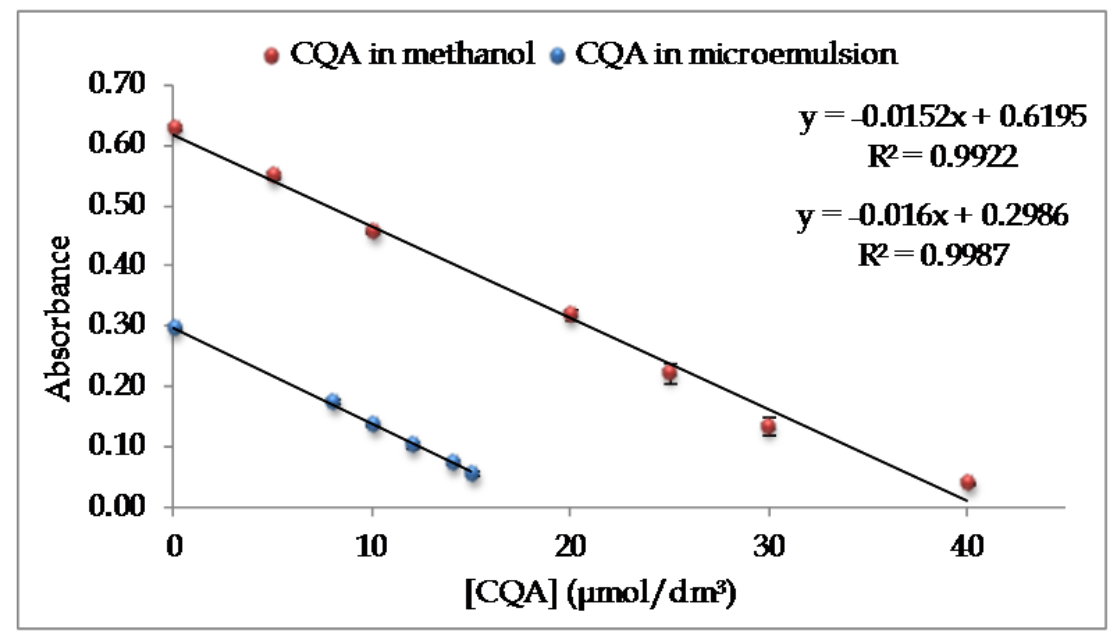

Fig. 14. The decay in DPPH as a function of the CQA concentration both in methanol and in microemulsion.

This shows the exchange between the inside of the microemulsion aggregate and the surrounding water. It also shows that the antioxidant is as effective (if any difference even slightly better) in the microemulsion as in the pure solvent methanol.

\subsubsection{Studies of the antioxidant properties of $\alpha$-tocopherol in the microemulsion}

For $\alpha$-tocopherol we could have it dissolved in the decane used for the microemulsion and had one other microemulsion with DPPH and just mixing these two microemulsions gave us a system with both components. This gave the same effect as if having them 
mixed in two pure decane solutions as seen in Figure 15. We could not have twice as high concentration of DPPH in one of the microemulsions to get the same initial concentration when mixed so that is why the concentration is lower. The concentration absorbance behavior is the same. The effect in the microemulsion is as good as in the solvent, if anything even slightly better. So this once again shows that there is an interchange between the inside and outside of the aggregates.

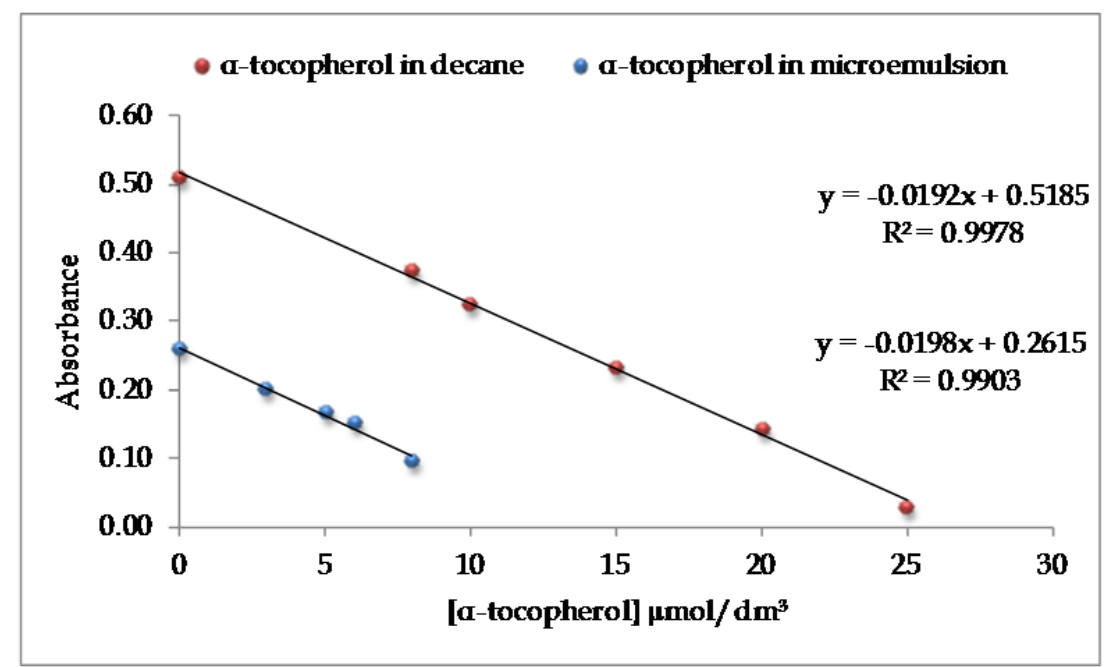

Fig. 15. The decay in DPPH as a function of the $\alpha$-tocopherol concentration both in decane and in microemulsion.

Once again we showed how there is an exchange between the microemulsion aggregate and the bulk. This is even a good visual way of showing how a purple solution mixed with a clear can become almost clear solution with a brownish color.

\subsubsection{Studies of the antioxidant properties of CQA and $\alpha$-tocopherol in the microemulsion}

Having showed that the two antioxidants worked well in the microemulsion when used individually the natural next step is to use them together. Like that there is a bonus in that they have opposite effect on the curvature and hence have smaller effect on the microemulsion boundaries. This was not an issue in the concentration range we used to be able to study the antioxidant effect as the concentrations were so low that they did not have any significant effect. If one would use much higher concentrations in formulations this would however be an advantage. It has earlier been reported that there is an additive effect by having these two antioxidants but that was for a reverse system (Sim et al., 2009). Our microemulsion is as previously stated oil-in-water in this temperature range. To study the antioxidant-effect an $\alpha$-tocopherol and CQA 1:1 containing microemulsion was mixed with a microemulsion containing DPPH. The effect of total antioxidant versus absorption is shown in Figure 16 and from this it is shown that the antioxidants work well together. 


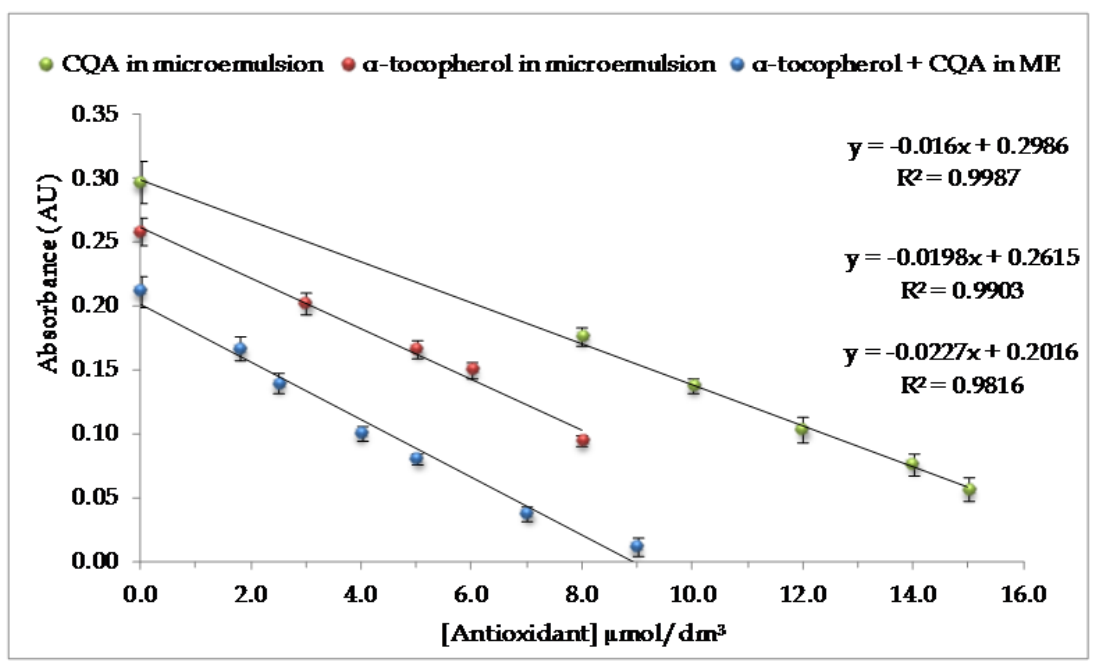

Fig. 16. The decay in DPPH as a function of the antioxidant concentration for CQA, $\alpha-$ tocopherol and the two combined.

By just comparing the decay it is seen how the two antioxidants can work together and by that have the same and even stronger effect with $1 / 4$ extra compared to their individual contribution. This is seen by their decay of -0.027 compared to the average of -0.0160 for CQA and -0.0198 for $\alpha$-tocopherol. As the two antioxidants has reverse effect on the phase boundaries more can be added and still have the temperature range of the model microemulsion.

\section{Conclusion}

We have here illustrated how convenient it is to use a model system to determine the effect of some added components to a microemulsion. We have shown both macroscopic and microscopic changes in the systems when adding these compounds. These properties of influencing the microemulsion would severely influence the use of the drug delivery system. Even if the macroscopic temperature effect is taken into consideration, the effect on the microscopic properties are important for properties like drug load and shelf-life. This shows the importance of always performing phase studies of the involved systems when adding components. It also shows the importance to investigate what happens with the system when it is loaded with an active component to see how it differs from a system without the drug. This may be masked to some degree by the more complex systems used today. These systems have much less temperature dependence so therefore the need to sometimes use model systems to better see the changes. We have seen how a hydrophobic compound, $\alpha$-tocopherol, a hydrophilic compound, CQA, and a compound that is mostly hydrophobic but has a solubility in water as well (20:1 solubility in decane compared to water), lidocaine influence the phase boundaries on the microemulsion. If one uses the ratio of surfactant tail to head as the reason for the curvature of the aggregate one can see the effect of adding these compounds as the effect they have on tails or the heads and in the case of lidocaine tails and to a small extent even the heads. This is illustrated in Figure 17. 


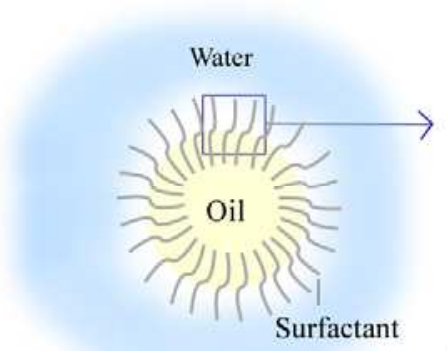

Surfactant

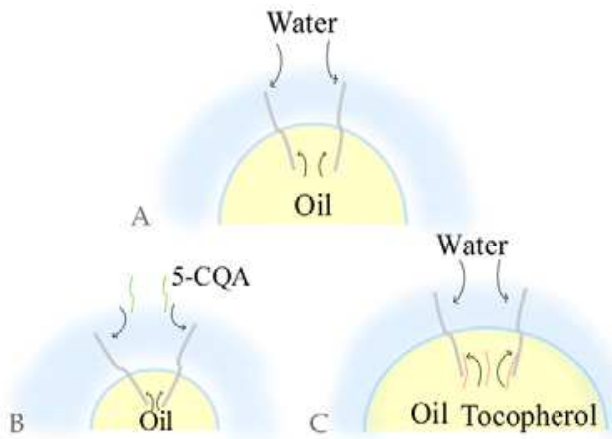

Fig. 17. Effect on the curvature of the surfactant film of the different components. The ingoing components are not set to scale. Here the micelle is shown and the close up of the surfactant and their interaction with water and oil standard system (A), the system with added CQA (B) and system with added tocopherol (C).

It is not determined yet if this is due to the penetration or general proximity to the heads and tails, but we know that it is not caused by the bulk charge in the case of CQA as sodium chloride at the same concentration did not have any significant effect.

Apart from the changes in phase boundary temperatures, the addition of these compounds also influence the temperature increase needed to change into a bicontinuous microemulsion and the growth with temperature and concentration. This influence may be important to be aware of when formulating so that it can be taken into consideration when planning. One can also use antioxidants in the microemulsions and they have the same effect as if they would be used in a pure solvent both for a hydrophobic compound as $\alpha$ tocopherol and a hydrophilic compound as CQA. We have with these experiments also illustrated that there is an interchange between the inside of the aggregate and the outside. Having a microemulsion or even an emulsion makes it possible to use both hydrophobic and hydrophilic antioxidants and by this have a more complex protection. This also minimizes the effect on the phase boundaries as they have reverse effect. The combination of the two antioxidants showed a synergetic effect of $1 / 4$. To further improve the knowledge one would like to study the specific interactions which the components have with the surfactant film. One would also use more substances in order to have a predictive quantitative model and not only a qualitative model. It would also be interesting to do long term tests with antioxidants and components that are sensitive to oxidation. This would eliminate any problem with an added dye.

\section{Acknowledgement}

This work was supported by Fundação para a Ciência e Tecnologia, (FCT) Portugal thrugh grant PEst-OE/EQB/LA0004/2011. JB would like to thank Fundação para a Ciência e Tecnologia, (FCT) Portugal for financing through post doc fellowship (SFRH/BPD729511/2006). 


\section{References}

Baciu, M., Holmes M. C., \& Leaver M. S. (2007). Morphological Transitions in Model Membrane Systems by the Addition of Anesthetics. The Journal of Physical Chemistry B, Vol. 111, No 4, (February 2007), pp. 909-917, ISSN 1520-6106.

Bagwe R. P., Kanicky, J. R, Palla, B. J. Patanjali, P. K. Shah, D. O. (2001). Improved drug delivery using microemulsions: rationale, recent progress, and new horizons. Crit Rev Ther Drug Carrier Syst, Vol. 18, No 1, pp. 77-140. ISSN: 0743-4863

Balogh, J. (2010). Determining scaling in known phase diagrams of nonionic microemulsions to aid constructing unknown. Advances in Colloid and Interface Science, Vol. 159, No 1, (August 2010) pp. 22-31, ISSN 0001-8686.

Balogh, J. Determination of Microemulsion Droplets size and anisotropy using Light Scattering, submitted 2011.

Balogh, J, Olsson U., Pedersen J. S., Kaper H., Wennerström H., Schillén K. \& Miguel M. (2010). Nonionic Microemulsions: Dependence of Oil Chain Length and Active Component (Lidocaine), Wiley-VCH Verlag GmbH \& Co. KGaA, pp. 59-87, ISBN 9783527632633.

Balogh, J, \& Pedersen J. S., Hórvölgyi, Z., \& Kiss, É. Eds. (2008). Investigating the Effect of Adding Drug (Lidocaine) to a Drug Delivery System Using Small-Angle X-Ray Scattering, Springer Berlin/Heidelberg, Vol. 135, pp. 101-106, ISBN 978-3-540-85133-2.

Balogh, J., \& Olsson U. (2007). Dependence on Oil Chain-Length of the Curvature Elastic Properties of Nonionic Surfactant Films: Droplet Growth from Spheres to a Bicontinuous Network. Journal of Dispersion Science and Technology, Vol. 28, No 2, (February 2007), pp. 223-230, ISSN 0193-2691.

Balogh, J., Kaper, H., Olsson, U., \& Wennerström, H. (2006). Effects of oil on the curvature elastic properties of nonionic surfactant films: Thermodynamics of balanced microemulsions. Physical Review E, Vol. 73, No 4, (April 2006) pp. 041506, ISSN 1550-2376.

Balogh, J., Marques, L., \& Lopes A. Natural antioxidants in a nonionic microemulsion, interactions and antioxidant activity to be submitted 2012.

Balogh, J., Olsson U., \& Pedersen J. S. (2006). Dependence on Oil Chain Length of the Curvature Elastic Properties of Nonionic Surfactant Films: Emulsification Failure and Phase Equilibria. Journal of Dispersion Science and Technology, Vol. 27, No 4 pp. 497-510, (February 2007), ISSN 0193-2691.

Balogh, J., Olsson U., \& Pedersen J. S. (2007). A SANS Contrast Variation Study of Microemulsion Droplet Growth. The Journal of Physical Chemistry B, Vol. 111, No 4, (February 2007) pp. 682-689, ISSN 1520-6106.

Basnet, P., Matushige, K., Hase, K., Kadota, S., \& Namba, T., (1996). Four di-O-caffeoyl quinic acid derivatives from propolis. Potent hepatoprotective activity in experimental liver injury models. Biological \& Pharmaceutical Bulletin, Vol. 19, No 11, (November 1996) pp. 1479-84. ISSN 1347-5215

Bissett, D. L., Chatterjee, R., \& Hannon, D. P. (1992). Protective effect of a topically applied anti-oxidant plus an anti-inflammatory agent against ultraviolet radiation-induced chronic skin damage in the hairless mouse. Journal of the Society of Cosmetic Chemists, Vol. 43, No 2, (March 1992) pp. 85-92.

Clifford, M., Clarke R. J., \&Macrae, R. (1985). Chlorogenic acids. In: Coffee, Elsevier Applied Science Publications, Vol 1, London, UK, ISBN 0-85334-368-3. 
De Maria, C. A. B., Trugo, L. C., Moreira, R. F. A., \& Werneck, C. C. (1994). Composition of green coffee fractions and their contribution to the volatile profile formed during roasting. Food Chemistry, Vol. 50, No 2, (October 1994) pp. 141-145, ISSN 0308-8146.

Fanun, M. (2009). Microemulsions: Properties and Applications, CRC Press, Surfactant science series, vol. 144, ISBN 9781420089592.

Gaonkar, A. G. \& Bagwe R. P. (2002). Microemulsions in Foods: Challenges and applications in Adsorption and aggregation of surfactants in solution, editors Mittal K. L. \& Shah D. O. 368-388 Marcel Dekker New York USA, ISBN 9780824708436.

Garti, N., Zakhaira, I., Spernath, A. Yaghmur, A., Aserin, A., Hoffman, R. E., \& Jacobs, L. Cabuil, V., Leviz, P., \& Treiner, C. Eds. (2004). Solubilization of water-insoluble nutraceuticals in nonionic microemulsions for water-based use, Springer Berlin/Heidelberg, Vol. 126, pp. 184-189, ISBN 978-3-540-20073-4.

Grampurohit, N., Ravikumar, P., \& Mallya, R. (2011). Microemulsions For Topical Use- A Review. Indian Journal of Pharmaceutical Education and Research, Vol. 45, No 1, (March 2011) 400-056.

Gupta, S. \& Moulik, S. P. (2008). Biocompatible microemulsions and their prospective uses in drug delivery. Journal of Pharmaceutical Sciences, Vol. 97, No 1: (January 2008) pp. 22-45, ISSN 1520-6017

Heuschkel, S., Goebel, A., \& Neubert, R. H. H. (2008). Microemulsions-modern colloidal carrier for dermal and transdermal drug delivery. Journal of Pharmaceutical Sciences, Vol. 97, No 2: (February 2008) pp. 603-631, ISSN 1520-6017.

Kahlweit, M. \& Strey, R. (1985). Phase Behavior of Ternary Systems of the Type H2O-OilNonionic Amphiphile (Microemulsions). Angewandte Chemie International Edition in English, Vol. 24, No 8, (August 1985) pp. 654-668, ISSN 1521-3773.

Kahlweit, M.; Strey, R., Firman, P., \& Haase, D. (1985) Phase behavior of ternary systems: water-oil-nonionic surfactants as near-tricritical phenomenon Langmuir, Vol 1, No 3 (March 1985) pp 281-288, ISSN 0743-7463.

Kogan, A. \& Garti, N. (2006). Microemulsions as transdermal drug delivery vehicles. Advances in Colloid and Interface Science, Vol. 123-126, No. Special Issue in Honor of Dr. K. L. Mittal, (November 2006) pp. 369-385, ISSN 0001-8686.

Kreilgaard, M. (2002). Influence of microemulsions on cutaneous drug delivery. Advanced Drug Delivery Reviews, Vol. 54, No Supplement 1, (November 2002) pp. 77-98, ISSN 0169-409.

Kreilgaard, M., Kemme, M. J. B., Burggraaf, J., Schoemaker, R. C., \& Cohen, A. F. (2001). Influence of a Microemulsion Vehicle on Cutaneous Bioequivalence of a Lipophilic Model Drug Assessed by Microdialysis and Pharmacodynamics. Pharmaceutical Research, Vol. 18, No 5: (May 2001) pp. 593-599, ISSN 0724-8741.

Krol, E. S, Kramer-Stickland K. A., \& Liebler D. C. (2000). Photoprotective actions of topically applied vitamin E. Drug Metabolism Reviews, Vol. 32, No 3-4, (January 2000) pp. 413-420. ISSN 1097-9883

Kunieda, H. and K. Shinoda. (1982). Phase behaviour in systems of non-ionic surfactant/ water/ oil/ around the hydrophile-lipophile-balance-temperature (HLBtemperature). Journal of Dispersion Science and Technology, Vol. 3, No 3, (October 1982) pp. 233-244, ISSN 0193-2691.

Kunieda. H., \& Solans C. (1997). Industrial applications of microemulsions, New York:Marcel Dekker Inc, vol. 199, pp. 1-17. ISBN 0824797957. 
Ky, C.-L, Louarn, J., Dussert, S., Guyot, B., Hamon, S., \& Noirot, M. (2001). Caffeine, trigonelline, chlorogenic acids and sucrose diversity in wild Coffea arabica L. and C. canephora P. accessions. Food Chemistry, Vol. 75, No 2, (November 2001) pp. 223230, ISSN 0308-8146.

Lawrence, M. J. \& Rees G. D. (2000). Microemulsion-based media as novel drug delivery systems. Advanced Drug Delivery Reviews, Vol. 45, No 1: (December 2000) pp. 89-121, ISSN 0169-409.

Le, T. D., Olsson, U., Wennerström, H., \& Schurtenberger, P. (1999). Thermodynamics of a nonionic sponge phase. Physical Review E, Vol. 60, No 4, (October 1999) pp. 43004309 ISSN1550-2376.

Leaver, M. S., Olsson, U., Wennerström, H., Strey, R. Emulsification failure in a ternary microemulsion. Journal de Physique II, Vol. 4, No. 3, (March 1994), pp.515-531, ISSN 1155-4312.

Leaver, M., Furo, I. \& Olsson, U. (1995). Micellar Growth and Shape Change in an Oil-inWater Microemulsion. Langmuir, Vol. 11, No 5. pp. 1524-1529 (May 1995) ISSN 0743-7463.

Lindman, B. Ed Stubenrauch, C.; (2008). Microemulsions : background, new concepts, applications, perspectives, Wiley-Blackwell, pp. XV, ISBN 978-1405-16-7.

Lopes, L. B., VanDeWall, H., Li, H. T., Vengupal, V., Li, H. K., Naydin, S., Hosmer, J., Levendusky, M., Zheng, H., Bentley, M. V. L. B., Levin, R.,\& Hass, M. A. (2010). Topical delivery of lycopene using microemulsions: Enhanced skin penetration and tissue antioxidant activity. Journal of Pharmaceutical Sciences, Vol. 99, No 3, (March 2010) pp. 1346-1357, ISSN 1520-6017.

Marques, L (2011), Natural antioxidants extraction and their incorporation into model pharmaceutical systems, Master Dissertation, FCT-UNL (Lisbon).

McVean, M. \& Liebler, D. C. (1999). Prevention of DNA photodamage by vitamin E compounds and sunscreens: Roles of ultraviolet absorbance and cellular uptake. Molecular Carcinogenesis, Vol. 24, No 3, (March 1999)pp. 169-176, ISSN 1098-2744.

Nabi, Z., Tavakkol, A., Soliman, N., \& Polefka, T. G. (1998). Bioconversion of tocopheryl acetate to tocopherol in human skin: use of human skin organ culture models. Pathophysiology, Vol. 5, No 1, (June 1998) pp. 190-190. ISSN 0928-4680.

Natella, F., Nardi, M., Belelli, F., \& Scaccini, C. (2007). Coffee drinking induces incorporation of phenolic acids into LDL and increases the resistance of LDL to ex vivo oxidation in humans. The American Journal of Clinical Nutrition, Vol. 86, No 3, ( September 2007) pp. 604-609. ISSN 0002-9165

Olsson, U. \& Schurtenberger, P. (1993). Structure, interactions, and diffusion in a ternary nonionic microemulsion near emulsification failure. Langmuir, Vol. 9, No 12, (December 1993) pp. 3389-3394, ISSN 0743-7463

Ramirez-Coronel, M. A., Marnet, N., V. S. Kumar Kolli, V. S. K., Roussos, S., Guyot, S. \& Augur, C. (2004). Characterization and Estimation of Proanthocyanidins and Other Phenolics in Coffee Pulp (Coffea arabica) by Thiolysis-High-Performance Liquid Chromatography. Journal of Agricultural and Food Chemistry, Vol. 52, No 5, (March 2004) pp. 1344-1349, ISSN 0021-8561.

Ramirez-Martinez, J.R. (1988). Phenolic compounds in coffee pulp: Quantitative determination by HPLC. Journal of the Science of Food and Agriculture, Vol. 43, No 2, (March 1988) pp. 135-144, ISSN 1097-0010. 
Rigotti, A. (2007). Absorption, transport, and tissue delivery of vitamin E. Molecular Aspects of Medicine, Vol. 28, No 5-6, (October 2007), pp. 423-436, ISSN 0098-2997.

Santos, P., Watkinson, A. C., Hadgraft, J., \& Lane, M. E. (2008). Application of Microemulsions in Dermal and Transdermal Drug Delivery. Skin Pharmacology and Physiology, Vol. 21, No 5, (September 2008) pp. 246-259, ISSN 1660-5527.

Scalbert, A. \& Williamson, G. (2000). Dietary Intake and Bioavailability of Polyphenols. The Journal of Nutrition, Vol. 130, No 8, (August 2000) pp. 2073S-2085S. ISSN 0022-3166.

Shinoda, K., \& Kunieda, H.; (1973) Conditions to produce so-called microemulsions. Factors to increase the mutual solubility of oil and water by solubilizer, Journal of Colloid Interface Science, Vol 42; No 2 (February 1973) pp 381-387. ISSN 0021-9797

Sim, W. L. S., Han, M. Y. \& Huang, D. (2009). Quantification of Antioxidant Capacity in a Microemulsion System: Synergistic Effects of Chlorogenic Acid with a-Tocopherol. Journal of Agricultural and Food Chemistry, Vol. 57, No 9, (May 2009) pp. 3409-3414, ISSN 0021-8561.

Sintov, A. C. \& Levy H.V. (2007). A microemulsion-based system for the dermal delivery of therapeutics. Innovations in pharmaceutical technology, Vol. 23, (December 2007) pp. 68-72.

Sottmann, T., \& Strey, R. (1996) Evidence of corresponding states in ternary microemulsions of water - alkane $-C_{i}$ E Journal of Physics: Condensed Matter Vol, 8,No 25 A (June 1996) pp. A39-A48. ISSN 1361-648X

Spernath, A. \& Aserin, A. (2006). Microemulsions as carriers for drugs and nutraceuticals. Advances in Colloid and Interface Science, Vol. 128-130, (December 2006): pp. 47-64, ISSN 0001-8686.

Trugo, L.C. \& Macrae, R. (1984). Chlorogenic acid composition of instant coffees. Analyst, Vol. 109, No 3, (March 1984) pp. 263-266, ISSN 0003-2654. 


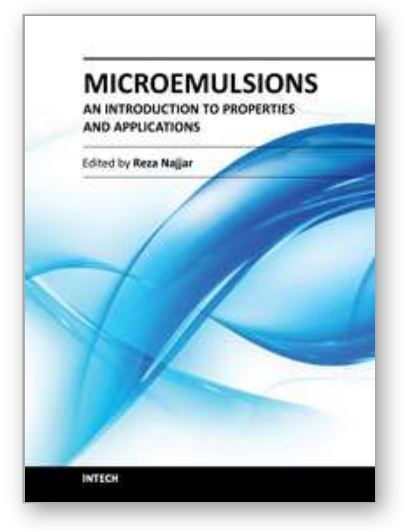

\author{
Microemulsions - An Introduction to Properties and Applications \\ Edited by Dr. Reza Najjar
}

ISBN 978-953-51-0247-2

Hard cover, 250 pages

Publisher InTech

Published online 16, March, 2012

Published in print edition March, 2012

The rapidly increasing number of applications for microemulsions has kept this relatively old topic still at the top point of research themes. This book provides an assessment of some issues influencing the characteristics and performance of the microemulsions, as well as their main types of applications. In chapter 1 a short introduction about the background, various aspects and applications of microemulsions is given. In Part 2 some experimental and modeling investigations on microstructure and phase behavior of these systems have been discussed. The last two parts of book is devoted to discussion on different types of microemulsion's applications, namely, use in drug delivery, vaccines, oil industry, preparation of nanostructured polymeric, metallic and metal oxides materials for different applications.

\title{
How to reference
}

In order to correctly reference this scholarly work, feel free to copy and paste the following:

Joakim Balogh, Luís Marques and António Lopes (2012). Nonionic Model Microemulsions to Study Interactions with Active Components and Antioxidant Activity, Microemulsions - An Introduction to Properties and Applications, Dr. Reza Najjar (Ed.), ISBN: 978-953-51-0247-2, InTech, Available from: http://www.intechopen.com/books/microemulsions-an-introduction-to-properties-and-applications/nonionicmodel-microemulsions-to-study-interactions-with-active-components-and-antioxidant-activity

\section{INTECH}

open science | open minds

\author{
InTech Europe \\ University Campus STeP Ri \\ Slavka Krautzeka 83/A \\ 51000 Rijeka, Croatia \\ Phone: +385 (51) 770447 \\ Fax: +385 (51) 686166 \\ www.intechopen.com
}

\author{
InTech China \\ Unit 405, Office Block, Hotel Equatorial Shanghai \\ No.65, Yan An Road (West), Shanghai, 200040, China \\ 中国上海市延安西路65号上海国际贵都大饭店办公楼 405 单元 \\ Phone: +86-21-62489820 \\ Fax: +86-21-62489821
}


(C) 2012 The Author(s). Licensee IntechOpen. This is an open access article distributed under the terms of the Creative Commons Attribution 3.0 License, which permits unrestricted use, distribution, and reproduction in any medium, provided the original work is properly cited. 